\title{
Quasi-solid-state solar rechargeable capacitors based on in-situ Janus modified electrode for solar energy multiplication effect
}

\author{
Peng Chen, Tian-Tian Li, Guo-Ran Li and Xue-Ping Gao*
}

\begin{abstract}
Solar energy is one of the most appealing clean energies to replace fossil fuel. However, the low power output is the bottleneck that hinders the effective usage of solar energy. Herein, we propose quasi-solid-state solar rechargeable capacitors for solar energy multiplication effect and effective application based on Janus modified electrode. The power output of solar energy could be magnified by an integrated unit, which consists of the hydrogel electrolyte, asymmetrically lyophilic/lyophobic Janus joint electrode, and efficient perovskite solar cells. Benefiting from the unique Janus structure, the quasi-solid-state device is capable of achieving outstanding solar energy conversion, storage and utilization with large power output of $500 \mathrm{~mW} \mathrm{~cm}{ }^{-2}$, which is about 50 times higher than that of conventional solar cells.
\end{abstract}

Keywords: solar energy, power multiplier, solar rechargeable capacitors, perovskite, quasi-solid-state

\section{INTRODUCTION}

Renewable energy is getting worldwide attention for environmental concerns, which also leads to an influx of electric vehicles (EVs) into the auto market. As a typical clean and cheap sustainable source, solar energy plays an important role in future energy systems to replace fossil fuels. In the future blueprint, solar irradiation is believed to be the desired energy resource to drive entirely greenenergy vehicles. However, solar energy suffers the low power density of $100 \mathrm{~mW} \mathrm{~cm}^{-2}$ (Air Mass 1.5 condition). When converted to electrical energy by solar cells, only $10-20 \mathrm{~mW} \mathrm{~cm}{ }^{-2}$ of solar power density could be obtained [1]. In particular, the momentary power would be tremendous in the start-up stage of EVs, which is impossible to be satisfied merely by traditional photovoltaics technologies [2]. Additionally, the intermittent and periodicity of solar irradiation are also inherent problems for the direct usage of solar energy. To remedy those shortcomings, combining the solar energy conversion parts with the energy storage parts like chemical power sources is considered as a promising approach.

Improving the practicability of solar irradiation is an ancient topic. Magnifying lens is the simplest and most spread solar thermal multiplier, as people can use it to ignite wood under sunlight. This simple but profound affair indicates that the practicability of solar energy could be efficiently enhanced by a gather/release approach in dimensional scale. In modern times, several electrical apparatuses have been developed to store and release solar energy in the form of electric energy. Inspired by the dimensional-scale solar thermal multiplier, we propose in this study a time-scale solar energy multiplier based on solar rechargeable capacitors (SRCs) to enhance the power output of solar energy. Compared with solar rechargeable batteries (SRBs) with high energy density [311], SRCs could magnify the power density of solar energy by storing/releasing in different time scales [12-34], which is in favor of various working stages of EVs. SRCs own special advantages in the flexible structure, quick response and long lifetime [34]. Apart from the application for high power density, it could also be incorporated with stretched soft device $[14,20]$, wearable self-powering systems $[13,16]$ and even novel fiber-shaped devices [31]. SRCs could combine capacitors with several kinds of photovoltaics, like traditional silicon batteries [33,34], new-generation organic solar cells $[25,28,32]$, dye-sensitized solar cells $[29,30]$ and perovskite solar cells (PSCs) [17-23,25-27], which makes this field very active. In particular, the state-of-art supercapacitors need polar electrolytes for providing sufficient power density, whereas the solvent might destroy the solar cell part. Meanwhile, the electrode fabrication also requires su-

Institute of New Energy Material Chemistry, School of Materials Science and Engineering, Nankai University, Tianjin 300350, China

*Corresponding author (email: xpgao@nankai.edu.cn) 
perior connected conductive network, which is not easy for the integrated structure. In order to build efficient SRC multiplier, aqueous electrochemical capacitors are desired for fast power response [35]. Meanwhile, state-ofart PSCs should be introduced for solar energy conversion due to their high efficiency. The key issue question is how to combine such aqueous electrochemical capacitors with water-sensitive PSCs into one multiplier unit.

In the past decade, asymmetrically designed Janus structures [36,37] have shown great potential in unidirectional oil/water separation [38], switchable ion transport [39], interfacial mass transfer [40] and energy storage [41]. "Janus" comes from the name of the god with two faces in ancient Roman mythology. In Chinese culture, "Tai Chi" indicates a similar philosophical view. Tai Chi includes "Yin" and "Yang", which are opposite but closely interlinked with each other. In the Janus structure, the features of the two sides are different or even inverse, e.g., lyophilic/lyophobic, which is perfectly in favor of fabricating dual-functionalized joint electrodes for SRCs. Herein, for the first time, we propose a Janus joint electrode with a lyophobic clean carbon top side and a lyophilic $\mathrm{NiCo}_{2} \mathrm{O}_{4}$ bottom side for SRCs. By in-situ preparation and modification, the dandelion-shaped $\mathrm{NiCo}_{2} \mathrm{O}_{4}$ can be deposited on only one side of the Janus joint electrode. After a surface treatment with perfluorinated silane on another side, the as-prepared Janus joint electrode could satisfy our demands ideally. Thanks to the superior lyophobic properties of perfluorinated silane, even aqueous hydrogel electrolyte can be used upon PSCs, which makes it possible to achieve highpower output SRCs. The integrated device would quickly get invalid within $1 \mathrm{~min}$ if the carbon paper is not Janus modified. When the quasi-solid-state $\mathrm{KOH} /$ polyvinyl alcohol (PVA) hydrogel is used as the electrolyte, the device can achieve a high specific capacity higher than $400 \mathrm{~F} \mathrm{~g}^{-1}$ and high overall efficiency of $4 \%$, which is significantly superior to other reported devices [15,17,19-25]. In particular, a superior high-power output of more than $500 \mathrm{~mW} \mathrm{~cm}^{-2}$ could be obtained, which is about 50 times higher than those of conventional solar cells. Those results demonstrate that the quasi-solid state SRCs with the Janus joint electrode would be of great significance for building reliable solar energy multiplier.

\section{EXPERIMENTAL SECTION}

\section{Janus joint electrode fabrication}

Commercial carbon paste was purchased from Shanghai MaterWin New Materials Corporation (China). Toray carbon paper was purchased from Canrd (China). $\mathrm{Ni}\left(\mathrm{NO}_{3}\right)_{2} \cdot 6 \mathrm{H}_{2} \mathrm{O}, \mathrm{Co}\left(\mathrm{NO}_{3}\right)_{2} \cdot 6 \mathrm{H}_{2} \mathrm{O}$, urea and $\mathrm{NH}_{4} \mathrm{~F}$ were purchased from J\&K chemical Tech (China). A piece of Toray carbon paper was cut into $3 \mathrm{~cm} \times 5 \mathrm{~cm}$ pieces. After being washed with acetone, the carbon paper was put on a hot plate at $140^{\circ} \mathrm{C}$. A polystyrene/chlorobenzene (PS/CB) solution $\left(100 \mathrm{mg} \mathrm{mL}^{-1}\right)$ was gently dropped on the carbon paper at the hotplate to prepare a one-side PS-protected carbon paper. The temperature in this stage is important for controlling the one-side deposition of PS. After the PS protection, the modified carbon paper was treated with $\mathrm{HNO}_{3}$ for $30 \mathrm{~min}$ and then put into a $50-\mathrm{mL}$ Teflon-lined stainless-steel autoclave. Then, $1.5 \mathrm{mmol}$ $\mathrm{Ni}\left(\mathrm{NO}_{3}\right)_{2} \cdot 6 \mathrm{H}_{2} \mathrm{O}, 3 \mathrm{mmol} \mathrm{Co}\left(\mathrm{NO}_{3}\right)_{2} \cdot 6 \mathrm{H}_{2} \mathrm{O}, 15 \mathrm{mmol}$ urea and $9 \mathrm{mmol} \mathrm{NH}_{4} \mathrm{~F}$ were dissolved in $40 \mathrm{~mL}$ distilled water under vigorous stirring to form a homogeneous solution. After being stirred for $0.5 \mathrm{~h}$, the solution was transferred into the autoclave and maintained at $130^{\circ} \mathrm{C}$ for $12 \mathrm{~h}$. Then, the reaction system was allowed to cool down to room temperature naturally. After the reaction, $\mathrm{NiCo}_{2} \mathrm{O}_{4}$ precursor was in situ deposited on both sides of the carbon paper. After a $\mathrm{CB}$ washing process, the PS side was cleaned and the $\mathrm{NiCo}_{2} \mathrm{O}_{4}$ precursor was grown on this side. The one-side $\mathrm{NiCo}_{2} \mathrm{O}_{4}$-deposited carbon paper was then obtained by annealing the above product at $300^{\circ} \mathrm{C}$ for $8 \mathrm{~h}$ in air. Before each step, the carbon paper should be weighted. Finally, a $1-2 \% 1 H, 1 H, 2 H, 2 H$-perfluorodecyltriethoxysilane/isooctane solution was sprayed on the clear top side, after being heated at $100^{\circ} \mathrm{C}$ for $10 \mathrm{~min}$, the surface of the top side should be wiped to finish the preparation of Janus joint electrode.

\section{PSCs fabrication}

Etched fluorine-doped tin oxide (FTO), $\mathrm{CH}_{3} \mathrm{NH}_{3} \mathrm{I}$ (MAI) and $\mathrm{CH}\left(\mathrm{NH}_{2}\right)_{2} \mathrm{I}$ (FAI) were purchased from YOUXUAN Tech (Yingkou, China), $\mathrm{PbI}_{2}$ and CsI were purchased from p-OLED Corporation (Xi'an, China). Etched FTO glasses were cleaned sequentially with detergent, deionized water, alcohol and acetone, followed by drying with $\mathrm{N}_{2}$ flow and $\mathrm{O}_{2}$ plasma treatment for $5 \mathrm{~min}$. A compact $\mathrm{TiO}_{2}$ layer was deposited by the hydrothermal reaction with 40 and $200 \mathrm{mmol} \mathrm{L}^{-1} \mathrm{TiCl}_{4}$ solution at $75^{\circ} \mathrm{C}$, and a porous $\mathrm{TiO}_{2}$ layer was deposited by spin-coating a diluted solution of $\mathrm{TiO}_{2}$ paste. The film was annealed at $120^{\circ} \mathrm{C}$ for $10 \mathrm{~min}$ and $500^{\circ} \mathrm{C}$ for $1 \mathrm{~h}$. The $\mathrm{FTO} / \mathrm{TiO}_{2}$ substrate was then transferred to an Ar-filled glove box. The perovskite layer was deposited on the $\mathrm{TiO}_{2}$ layer by a spincoating method. In detail, $461 \mathrm{mg} \mathrm{PbI}, 151 \mathrm{mg}$ MAI (or $166 \mathrm{mg}$ FAI), $13 \mathrm{mg}$ CsI and $156 \mathrm{mg}$ dimethyl sulfoxide

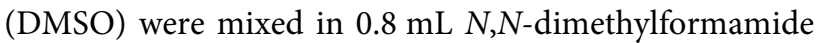


(DMF). Perovskite precursor solution $(50 \mu \mathrm{L})$ was dropped on the substrate and spin-coated at $1000 \mathrm{rpm}$ for $12 \mathrm{~s}$ and $4000 \mathrm{rpm}$ for $20 \mathrm{~s}$ with diethyl ether $(1 \mathrm{~mL})$ being dripped on the substrates $10 \mathrm{~s}$ prior to the end of the process. The substrates were then annealed at $120^{\circ} \mathrm{C}$ for $10 \min \left(150^{\circ} \mathrm{C}\right.$ for 20 min with $\left.\mathrm{FAI}\right)$ to obtain crystalline perovskite films. After cooling down, carbon paste was coated on the top of perovskite by a doctor-blading method, followed by being heated at $120^{\circ} \mathrm{C}$ for $15 \mathrm{~min}$.

\section{SRC assembling and measurements}

Aqueous electrolyte was prepared by dissolving $1.68 \mathrm{~g}$ $\mathrm{KOH}$ in $10 \mathrm{~mL}$ distilled water. As for the hydrogel electrolyte, $1 \mathrm{~g}$ PVA was added in $15 \mathrm{~mL}$ distilled water at $95^{\circ} \mathrm{C}$ under stirring. After the PVA was dissolved, $1 \mathrm{~g}$ $\mathrm{KOH}$ was added into the viscous gel solution under vigorous stirring for $12 \mathrm{~h}$. The clear side of the Janus joint electrode was pasted on the PSC substrate by using carbon paste. After being heated at $120^{\circ} \mathrm{C}$ for $15 \mathrm{~min}$, the unit was left to cool down to room temperature. A certain amount of aqueous electrolyte or hydrogel electrolyte was then added to the $\mathrm{NiCo}_{2} \mathrm{O}_{4}$ side of the Janus joint electrode, after that, another $\mathrm{NiCo}_{2} \mathrm{O}_{4}$ electrode was capped on the top to finish the assembling (a piece of separator was needed when using aqueous electrolyte). All the devices were tested under air condition using a Keithley 2400 source meter and a Newport Oriel sol2A solar simulator $(300 \mathrm{~W})$ and Zolix solar simulator. The light intensity was calibrated by using the $91150 \mathrm{~V}$ Reference Cell and Meter (ORIEL instrument) and it was $100 \mathrm{~mW} \mathrm{~cm}^{-2}$ before the device testing. The device performance parameters were obtained from the currentvoltage curves of the solar cells under illumination. An area of $0.1 \mathrm{~cm}^{2}$ was used to measure the power conversion efficiency. When testing the high-power properties, little photoactive area $\left(0.01 \mathrm{~cm}^{2}\right)$ was applied to obtain the high areal power density.

\section{Calculations}

The power conversion efficiency (PCE) of the PSC was calculated according to

$\mathrm{PCE}=J_{\mathrm{sc}} \times V_{\mathrm{oc}} \times \mathrm{FF} / P \times 100 \%$,

where $J_{\mathrm{sc}}, V_{\mathrm{oc}}, \mathrm{FF}$ and $\mathrm{P}$ are the short-circuit current density $\left(\mathrm{mA} \mathrm{cm}^{-2}\right)$, open-circuit voltage $(\mathrm{V})$, fill factor, and incident light power density $\left(100 \mathrm{~mW} \mathrm{~cm}^{-2}\right)$, respectively. The photoactive area is $0.1 \mathrm{~cm}^{2}$ unless otherwise stated.

The electric capacity for capacitor part was calculated according to

$C_{\mathrm{F}}=J \times t / U$, where $C_{\mathrm{F}}, J, t$ and $U$ are the capacity of supercapacitor $\left(\mathrm{F} \mathrm{g}^{-1}\right)$, discharge current density $\left(\mathrm{A} \mathrm{g}^{-1}\right)$, time of discharge process $(\mathrm{s})$ and voltage of supercapacitor $(\mathrm{V})$, respectively.

The overall energy-conversion efficiency for the entire integrated unit was calculated according to

$\eta=E_{\text {discharge }}(P \times S \times t) \times 100 \%$,

where $E_{\text {discharge }}, P, S$ and $t$ are the discharge energy of supercapacitor ( $\mathrm{mW} \mathrm{h}$, from Land machine), light power density $\left(100 \mathrm{~mW} \mathrm{~cm}{ }^{-2}\right)$, photoactive area of PSCs $\left(\mathrm{cm}^{2}\right)$ and photo-charge time $(\mathrm{h})$, respectively.

The average power output of SRC $\left(P_{\text {ave }}\right)$ was calculated according to

$P_{\text {ave }}=0.5 \times V_{\text {SRC }} \times I_{\text {discharge }} / S$,

where 0.5 is the coefficient for average voltage during the whole discharge process, $V_{\mathrm{SRC}}$ is the voltage of SRC device $(\mathrm{V})$ and $I$ is the discharge current $(\mathrm{mA}), S$ is the active area of the PSC part $\left(\mathrm{cm}^{2}\right)$.

\section{RESULTS AND DISCUSSION}

In order to build concise and effective SRCs, an integrated design without excess electronic elements is preferred [8]. Herein, we chose a joint electrode mode (JEM) structure to fabricate the integrated devices [3]. In a typical JEMbased integrated SRC, the joint carbon electrode acts as the counter electrode for the PSCs. Simultaneously, it also acts as the positive electrode on the energy storage side. Since the porous positive electrode demands sufficient infiltration of the electrolyte, the electrolyte inevitably undermines the water-sensitive perovskite layer in common cases. In our integrated devices, the bottom side is designed as host for active materials, so that it should be lyophilic to ensure good wettability of active materials with electrolyte. Meanwhile, the top side should be lyophobic to protect the perovskite layer out of the interference from electrolyte. Therefore, such dualfunctionalized Janus joint electrode should be introduced to satisfy such requirement, thus making it possible to fabricate SRCs based on effective PSCs and electrochemical capacitors.

Fig. 1a briefly introduces and compares the solar energy density, whether it is utilized by solar cells directly or being stored/released through capacitors. Generally, the initial power density of AM 1.5 sunlight is $100 \mathrm{~mW} \mathrm{~cm}^{-2}$, which is a physical limitation of photovoltaics. As a result, the electric energy density would be about $10-20 \mathrm{~mW} \mathrm{~cm}^{-2}$ when converted from solar irradiation by solar cells. Such a low power density is not suitable for practical usage. A feasible solution to improve the power density is to introduce a store/release working mode in 
a

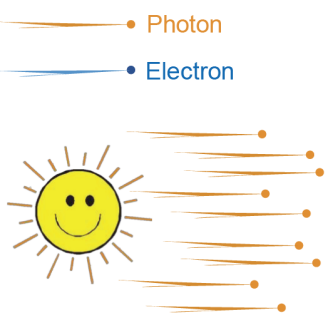

AM $1.5100 \mathrm{~mW} \mathrm{~cm}^{-2}$
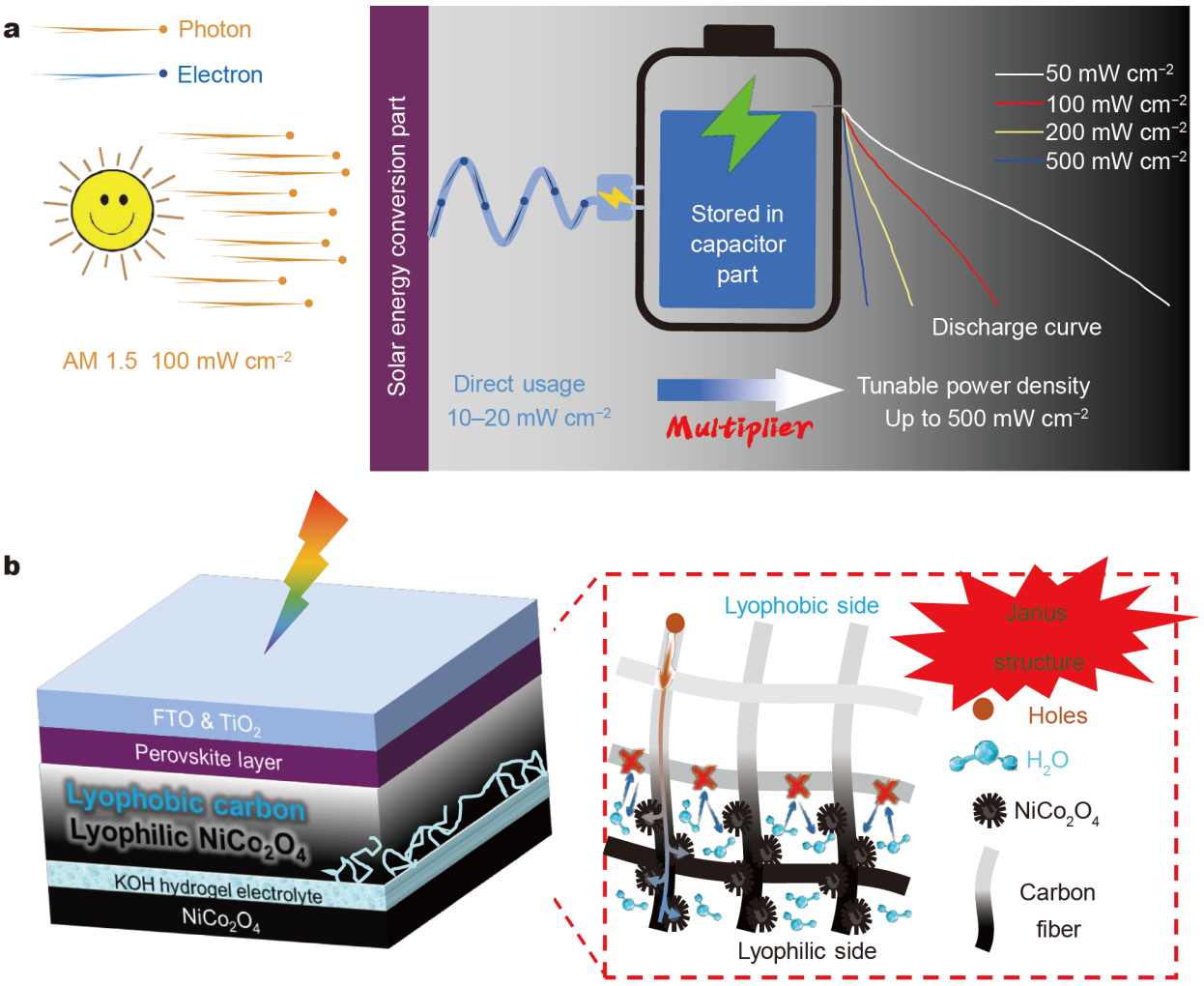

Figure 1 (a) The graphic introduction and comparison of solar energy power output when utilized by different paths, directly or being stored/ released through capacitors. (b) Schematic diagram of the integrated SRCs based on the Janus joint electrode.

SRCs. When the solar energy is converted into electric energy by solar cells, the capacitors in SRCs could store those photo-induced charges as chemical energy simultaneously. After a period of storage, the accumulated chemical energy could be released as electric energy with tunable current and power density. In this way, we can realize the power density multiplication of solar energy. It must be mentioned that the power-density multiplication in the device still follows the energy conservation law, and the total energy is not increased. The high-power-density multiplication depends highly on the store/release mode in the fabricated device.

It is generally known that using transition metal oxides with high capacity can improve the energy density and power output. Based on this consideration, we chose $\mathrm{NiCo}_{2} \mathrm{O}_{4}$ to store solar energy and construct the power multiplier. Fig. S1 schematically shows the detailed preparation process of the Janus joint carbon paper electrode. Generally, PS/CB solution is dropped on the carbon paper to prepare a one-side PS-protected carbon paper. The one-side $\mathrm{NiCo}_{2} \mathrm{O}_{4}$-deposited carbon paper was then obtained by a hydrothermal reaction and CBwashing process for cleaning the PS side. Finally, a per- fluorinated silane/isooctane solution was sprayed on the clean side to achieve hydrophobicity of Janus joint carbon paper electrode. Fig. $1 \mathrm{~b}$ shows the schematic diagram of the integrated SRCs based on the Janus joint electrode. Electrons and holes can transfer freely through the carbon fibers of the Janus joint electrode, while the troublesome solvent is blocked away from the PSC side. It should be mentioned that the perfluorinated silane would affect the charge-transfer process. Fortunately, the perfluorinated silane layer is covered on the outside of carbon fiber, while the electrons and holes are injected and transported inside the carbon fiber, so it is rational to say that the block effect of the perfluorinated silane is acceptable and less-influential. Under illumination, the perovskite layer would absorb photon and produce pairs of electron/hole. Holes would be transmitted through the Janus joint electrode, while the photo-generated electrons would be transferred to the negative electrode via external circuit. In this process, the active $\mathrm{NiCo}_{2} \mathrm{O}_{4}$ materials would be oxidized by holes in the positive side [42-45], and reduced by photo-generated electrons in the negative side, leading to the conversion and storage of solar energy as chemical energy in the electrochemical capacitors. During 
the discharge process, the stored chemical energy could be released as electrical energy with a tunable power output via external circuit to drive electronic devices. Therefore, such designed SRC device is capable of converting and storing the solar energy under irradiation, and releasing electric energy subsequently with a magnified power density.

Scanning electron microscopy (SEM) images and energy dispersive spectra (EDS) mapping clearly show the surface morphology and asymmetrically deposition of $\mathrm{NiCo}_{2} \mathrm{O}_{4}$ within the Janus joint electrode (Fig. 2a). More details about SEM and EDS images during the preparation process are presented in Fig. S2. After CB washing and annealing, the dandelion-shaped morphology of $\mathrm{NiCo}_{2} \mathrm{O}_{4}$ is retained while the PS side is entirely removed, realizing the unique structure of the Janus electrode. $\mathrm{X}$ ray diffraction (XRD) test (Fig. S3) shows that the asprepared material has the typical face-centered cubic structure of $\mathrm{NiCo}_{2} \mathrm{O}_{4}$. Contact angle measurement and digital images (Fig. 2b and c) confirm that the two sides of the Janus joint electrode have opposite wettability. In particular, the bottom side with $\mathrm{NiCo}_{2} \mathrm{O}_{4}$ is lyophilic that enables electrolyte to penetrate into the positive electrode, while the top side is lyophobic to prevent the solvent from passing through the joint electrode. Benefiting from the tailored asymmetrical Janus structure, a quasi-solid-state hydrogel electrolyte can now be used upon PSCs to construct SRCs, which would be pivotal for high power output as solar energy multiplier.

Highly efficient and stable energy conversion and storage are the key functions for the SRC multiplier.
Therefore, we firstly evaluated the electric performance and stability of solar energy conversion in PSCs and energy storage in the Janus electrode, respectively. The $\mathrm{CH}_{3} \mathrm{NH}_{3} \mathrm{PbI}_{3}$ (MA-type) hole-transporting-layer free perovskite solar cell shows an impressive high PCE $(16.46 \%)$. On the other hand, the stability is not satisfactory. In order to improve the stability, formamidine (FA) was introduced to replace MA (Fig. S4). When the Janus joint electrode as counter electrode is used in FAtype PSCs, the short-circuit current and fill factor decrease slightly due to the increased resistance (Fig. 3a). Next, the light stability of the PSCs was examined from continuous irradiation, which shows that the open circuit voltage $\left(V_{\text {oc }}\right)$ and PCE were steady during $1000 \mathrm{~min}$ (Fig. $3 \mathrm{~b}$ ), and $90 \%$ of the initial value could be maintained.

Since the above PSC exhibited good stability, we tested the electrochemical performance of the Janus electrode, including the capacity, cyclic stability and rate capability. It is clearly shown in the cyclic voltammograms (CVs) (Fig. 3c) that the Janus joint electrode exhibits a large electrochemical capacity, contributed from the redox reactions of $\mathrm{NiCo}_{2} \mathrm{O}_{4}$, quite different from pure carbon paper. The charge-discharge curves of both the bare carbon and Janus electrode are shown in Fig. S5. When fabricated as a $\mathrm{NiCo}_{2} \mathrm{O}_{4} \mid$ hydrogel electrolyte $\| \mathrm{NiCo}_{2} \mathrm{O}_{4}$ full capacitor, the device demonstrates excellent performance (initial capacity of about $404 \mathrm{~F} \mathrm{~g}^{-1}, 372 \mathrm{~F} \mathrm{~g}^{-1}$ after 1000 cycles at $1 \mathrm{~A} \mathrm{~g}^{-1}$, Fig. 3c). In particular, a high capacity of $319 \mathrm{~F} \mathrm{~g}^{-1}$ still retains even when the current density increases from 1 to $20 \mathrm{~A} \mathrm{~g}^{-1}$ (Fig. 3d), indicating

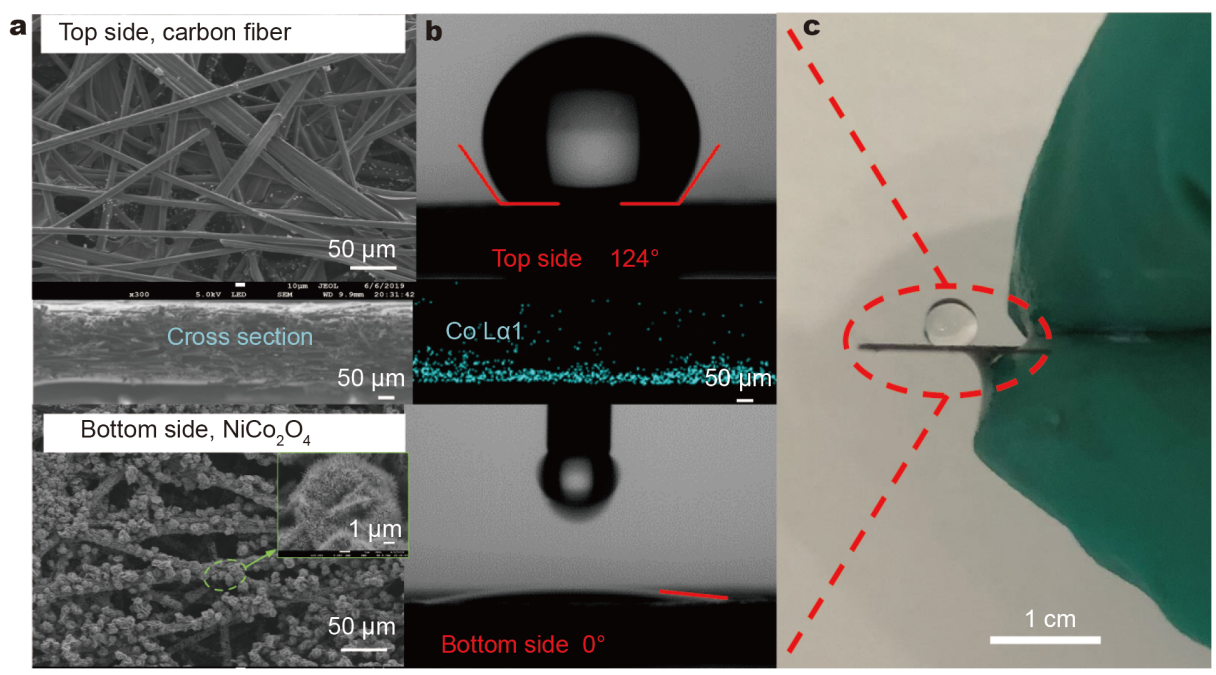

Figure 2 (a) SEM images and EDS mapping of Janus joint electrode. (b) Contact angle test images of different sides for the Janus joint electrode. (c) Digital image of the Janus joint electrode with water drop on both sides. 

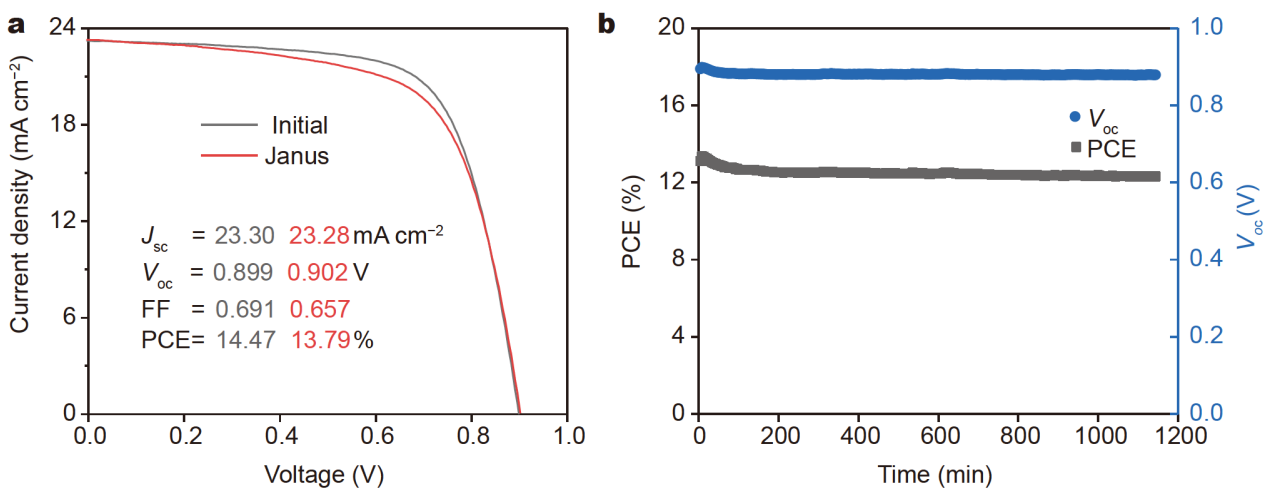

Current density
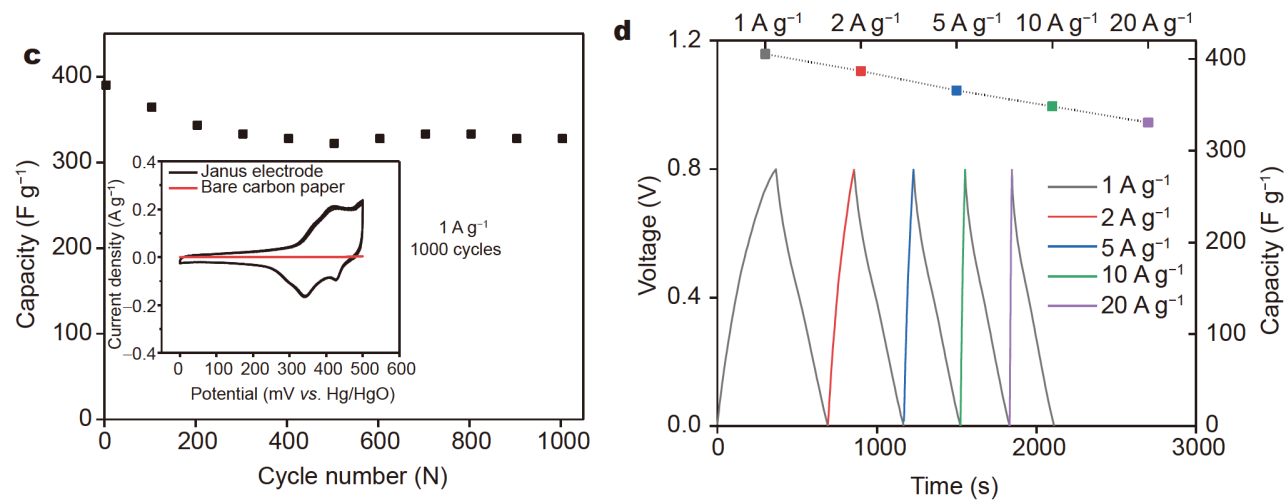

Figure 3 (a) $J$ - $V$ curves for the FA type PSCs with the Janus joint electrode and normal carbon paper as counter electrodes. (b) PCE and $V_{\text {oc }}$ changing tendency during illumination for $1000 \mathrm{~min}$. (c) Capacity retention of the Janus electrode during $1000 \mathrm{cycles}$ at $1 \mathrm{~A} \mathrm{~g}^{-1}$. Inset shows the CVs of the bare carbon paper and Janus joint electrode at a scan rate of $0.1 \mathrm{mV} \mathrm{s}^{-1}$ within the potential range of $0-0.5 \mathrm{~V}(v s . \mathrm{Hg} / \mathrm{HgO})$. (d) Voltage-time profiles of the Janus joint electrode at high current densities.

the high rate capability of the capacitor. Therefore, on the basis of efficient PSCs, highly conductive quasi-solid-state hydrogel electrolyte, and most importantly, the Janus joint electrode, we can ensure the working feasibility of SRC multiplier devices.

The photo-charge characteristics of the integrated SRCs were tested by using a solar simulator (Zolix, China) and automatic battery tester system (Land, China). The integrated SRCs were placed under AM 1.5 illumination for photo-charging, and the charge rate was determined by the active area of PSCs. When the voltage of SRCs exceeded $0.8 \mathrm{~V}$, the light source was turned off and the Land system was subsequently switched to galvanostatic discharge process. Firstly, the charge/discharge current density of $1 \mathrm{~A} \mathrm{~g}^{-1}$ and photoactive area of $0.07 \mathrm{~cm}^{2}$ were used to evaluate the voltage profiles in the galvanostatic/ photo-charge and discharge processes. As shown in Fig. 4a, the integrated SRCs can work under power-supply and photo-charge modes, presenting similar charge/discharge voltage profiles. Of course, a "voltage tail" is ob- served in the high voltage range under photo-charge mode, which is described as a self-adjust property from the diode characteristics of PSCs [3]. Herein, the charge current and voltage are controlled by PSCs. When the voltage increases, the charge current decreases simultaneously. This smart real-time response photo-charge mode could endure the large polarization in the electrochemical reaction and diffusion processes, especially in the case that large current density is needed. Different photoactive areas of $0.07,0.14,0.21,0.35 \mathrm{~cm}^{2}$ were used to investigate the voltage and capacity response at different photo-charge rates (Fig. S6a). Obviously, the larger the area is applied, the faster the charge process is obtained. Importantly, the large discharge capacity is obtained under photo-charge mode with large area, superior to that under power-supply mode (Fig. S6b).

After efficient conversion and storage of solar energy, the fast energy releasing process should be concerned for verifying the function of the SRC multiplier with the high-power output. According to Equation (4), the power 

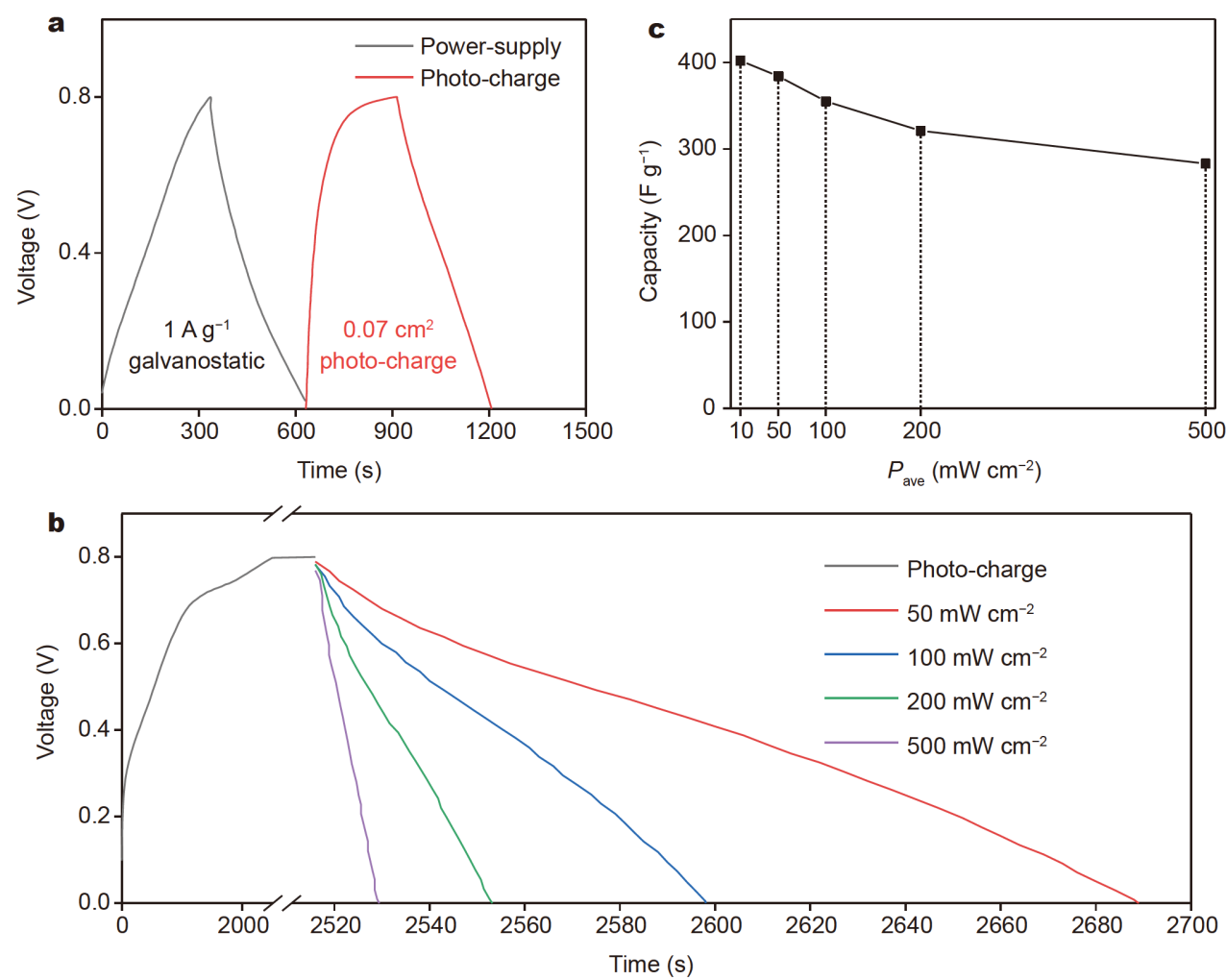

Figure 4 Voltage-time curves of the integrated SRCs at (a) power-supply and photo-charge modes and (b) photo-charge mode with different output power densities. (c) Voltage profiles of the integrated SRCs at different output power densities.

density can be adjusted by changing two major parameters, the discharge current and the active area. Firstly, the mass loading of the $\mathrm{NiCo}_{2} \mathrm{O}_{4}$ active materials is optimized as $5 \mathrm{mg}$ for high-power output tests (Fig. S6c), based on the evaluation of energy storage efficiency, capacity, and electrode polarization. Secondly, the average areal power density $P_{\text {ave }}$ in the discharge process was calculated from the discharge power output and photoactive area to make comparison. By fixing the discharge current and tuning the photoactive area, we can obtain variable output power densities. However, if large active area is used, electrode polarization is become serious for capacitors and PSCs, inevitably leading to the deviation of the power density [25]. When the same discharge current and variable area are used, the output power density decreases gradually with the increasing active area, as presented in Fig. S7. At the same discharge current of $1.2 \mathrm{~mA}$, the power density decreases from $7 \mathrm{~mW} \mathrm{~cm}^{-2}$ $\left(0.07 \mathrm{~cm}^{2}\right)$ to $1.4 \mathrm{~mW} \mathrm{~cm}{ }^{-2}\left(0.35 \mathrm{~cm}^{2}\right)$. Therefore, the power density of the integrated device was calculated from small active area, in order to explore the maximum potential capability of the power density. As shown in Fig. $4 \mathrm{~b}$ and $\mathrm{c}$, the voltage of the device reaches $0.8 \mathrm{~V}$ gradually in the photo-charge process. When discharged at higher currents, different power output densities can be obtained. In real scenario application, the power output could be adjusted to meet diverse demands from longtime power supplying to fast instantaneous response. In this work, we tested the power density of up to $500 \mathrm{~mW} \mathrm{~cm}^{-2}$, which reaches the limitation of experimental condition. In fact, it could be much higher with larger discharge current. Obviously, the discharge curves are varied along with the output power density from 50 to $500 \mathrm{~mW} \mathrm{~cm}^{-2}$. Owing to the well-designed structure, the discharge capacity retains $70.4 \%$ of the initial value (from 402 to $283 \mathrm{~F} \mathrm{~g}^{-1}$ ). Therefore, the integrated SRCs could offer the desired high-power output due to the effective photo-charge mode and well-designed Janus electrode, verifying a competent solar energy multiplier.

Working stability is an important issue for energy conversion and storage devices. For the integrated SRCs, 50 cycles at power-supply mode and 50 cycles at photocharge mode were tested to confirm the long-term operating stability. As presented in Fig. 5a, during the 100 cycles, the identical shape of voltage-time curves is maintained, showing a stable working status. Moreover, 

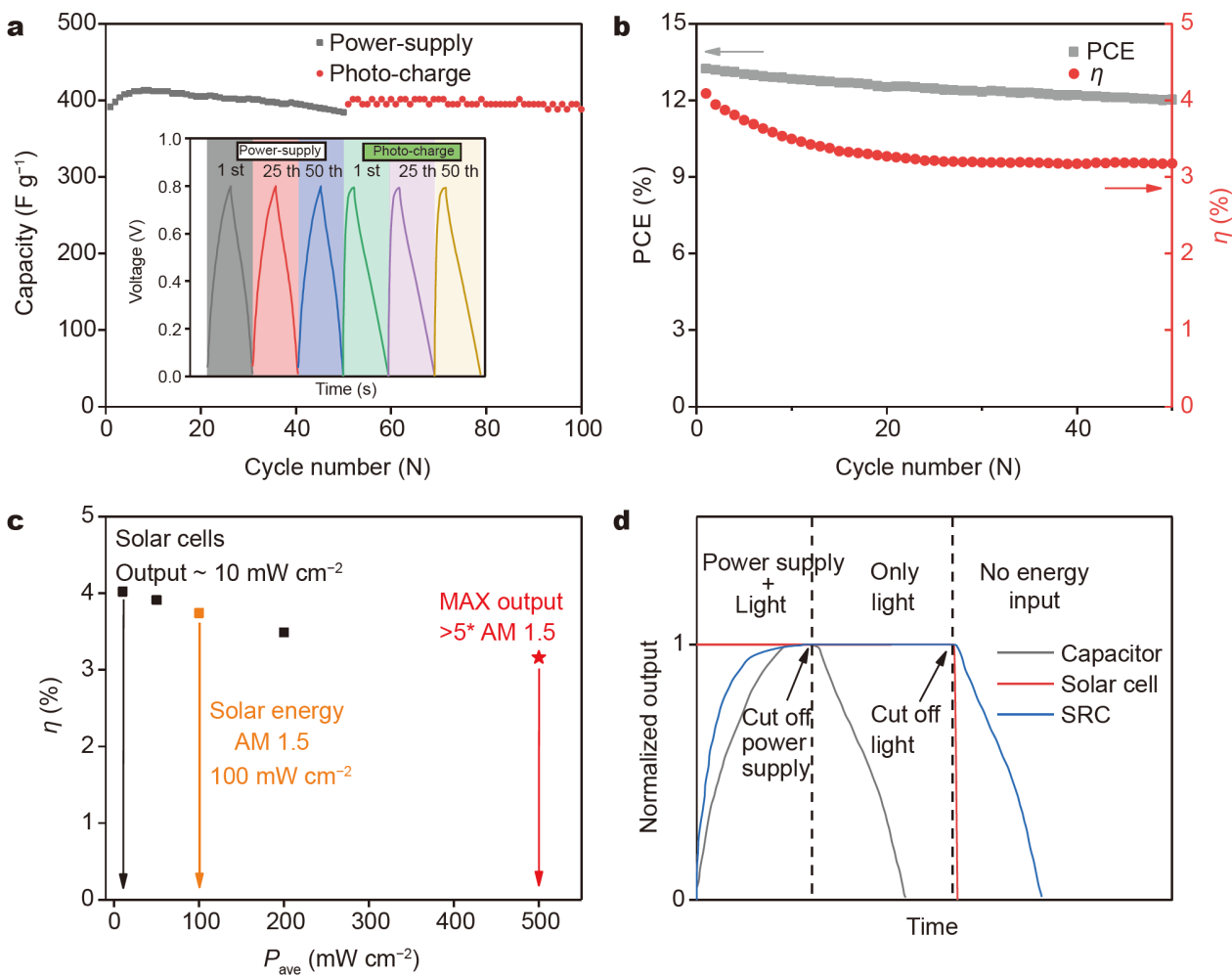

Figure 5 (a) Cyclic tests of the integrated SRCs at power-supply and photo-charge modes. (b) PCE and overall efficiency during the cyclic test of the integrated SRCs. (c) Overall efficiency performance of the integrated SRCs under different power outputs. (d) Simulated operating condition tests of the capacitors, solar cells and SRCs.

the discharge capacities decrease slightly during the cycling, indicating that the integrated SRCs have a good working stability. Since PCE is a primary concern of photovoltaics, the changing tendencies of overall efficiency $(\eta)$ for the integrated device and PCE for PSCs were tested simultaneously (Fig. 5b). As presented, the high $\eta$ of $4.08 \%$ in the initial cycle is obtained, which is the best value for the integrated SRCs. During the 50 photo-charge cycles, both PCE and $\eta$ suffer a slight decay. As reported in the previous work [3], we believe that the strategy of adjusting voltage range during the photocharge process to be around the maximum power point of solar cells would be helpful for improving the efficiency.

For the solar energy multiplier, the efficiency under high power condition is of particular concern. Under the large discharge power density, the device could still work with high energy conversion efficiency. When the output power density exceeds $100 \mathrm{~mW} \mathrm{~cm}^{-2}$, identical to the initial solar irradiation, high $\eta$ of $3.7 \%$ is still maintained. Even with the output power density of $500 \mathrm{~mW} \mathrm{~cm}^{-2}$, which is 5 times higher than solar energy and about 50 times higher than solar cells, the integrated SRCs can still work effectively with $\eta$ of $3.1 \%$ (Fig. 5c). The cyclic photo-charge stability of the device under various power densities was also tested and the details are shown in Fig. S8. It is clear that the integrated device could maintain robust performance based on the evaluation of the overall efficiency decay during cycling. A simulated operating condition test was made to check the operating performance of the device in real scenario. As shown in Fig. 5d, after the power supply is cut off, the capacitors run out of chemical energy quickly, while the integrated SRCs and PSCs can still work for a long time under light illumination. In real outdoor work conditions, sunlight is fluctuant dramatically. Especially, when the light is hidden by clouds, the PSCs become inoperative immediately, while the integrated SRCs can still provide emergency power supply. In this way, the SRC multiplier based on the Janus joint electrode designed in the current stage can achieve smart photo-charge manipulation, convert and store solar energy efficiently and utilize solar energy without suffering the fluctuation of solar irradiation. Importantly, the device provides high and tunable power 
output to satisfy different demands.

\section{CONCLUSIONS}

In summary, in this study, we propose an integrated SRC for solar energy multiplication effect based on efficient PSCs, in situ modified Janus joint electrode, and quasisolid-state hydrogel electrolyte. Owing to the tailored Janus structure of joint electrode, highly conductive quasi-solid-state hydrogel electrolyte can be used upon water-sensitive PSCs, which makes it possible to fabricate SRCs with high-power output. With optimized designation, our device can achieve an output power density of more than $500 \mathrm{~mW} \mathrm{~cm}^{-2}$, which is 5 times higher than solar irradiation and about 50 times higher than solar cells. These excellent performances prove that the integrated SRC multiplier designed in this study has great potential to meet high-power output demands, including the start-up stage of EVs. Benefiting from the efficient photo-charge mode, the integrated SRCs could achieve a high overall efficiency of $4.08 \%$ and a large capacity of $400 \mathrm{~F} \mathrm{~g}^{-1}$, which is the best performance in the integrated SRCs to the authors' best knowledge. We hope that these superior performances of the integrated SRC multiplier in this work could bring a breakthrough in the field of solar energy conversion, storage, and utilization in future applications.

\section{Received 23 February 2020; accepted 31 March 2020;} published online 5 June 2020

1 Green MA, Hishikawa Y, Dunlop ED, et al. Solar cell efficiency tables (version 53). Prog Photovolt Res Appl, 2019, 27: 3-12

2 Simon P, Gogotsi Y, Dunn B. Where do batteries end and supercapacitors begin? Science, 2014, 343: 1210-1211

3 Chen P, Li GR, Li TT, et al. Solar-driven rechargeable lithiumsulfur battery. Adv Sci, 2019, 6: 1900620

$4 \mathrm{Hu}$ Y, Bai Y, Luo B, et al. A portable and efficient solarrechargeable battery with ultrafast photo-charge/discharge rate. Adv Energy Mater, 2019, 9: 1900872

5 Paolella A, Faure C, Bertoni G, et al. Light-assisted delithiation of lithium iron phosphate nanocrystals towards photo-rechargeable lithium ion batteries. Nat Commun, 2017, 8: 14643

6 Lei B, Li GR, Chen P, et al. A solar rechargeable battery based on hydrogen storage mechanism in dual-phase electrolyte. Nano Energy, 2017, 38: 257-262

7 Yu M, Ren X, Ma L, et al. Integrating a redox-coupled dyesensitized photoelectrode into a lithium-oxygen battery for photoassisted charging. Nat Commun, 2014, 5: 5111

8 Gurung A, Qiao Q. Solar charging batteries: Advances, challenges, and opportunities. Joule, 2018, 2: 1217-1230

9 Liu P, Cao Y, Li GR, et al. A solar rechargeable flow battery based on photoregeneration of two soluble redox couples. ChemSusChem, 2013, 6: 802-806

10 Liao S, Zong X, Seger B, et al. Integrating a dual-silicon photo- electrochemical cell into a redox flow battery for unassisted photocharging. Nat Commun, 2016, 7: 11474

11 Schmidt D, Hager MD, Schubert US. Photo-rechargeable electric energy storage systems. Adv Energy Mater, 2016, 6: 1500369

12 Intermite S, Arbizzani C, Soavi F, et al. Perovskite solar cellelectrochemical double layer capacitor interplay. Electrochim Acta, 2017, 258: 825-833

$13 \mathrm{Ng} \mathrm{CH}$, Lim HN, Hayase S, et al. Potential active materials for photo-supercapacitor: A review. J Power Sources, 2015, 296: 169185

14 Zhang F, Li W, Xu Z, et al. Highly flexible and scalable photorechargeable power unit based on symmetrical nanotube arrays. Nano Energy, 2018, 46: 168-175

15 Liang J, Zhu G, Wang C, et al. An all-inorganic perovskite solar capacitor for efficient and stable spontaneous photocharging. Nano Energy, 2018, 52: 239-245

16 Li C, Cong S, Tian Z, et al. Flexible perovskite solar cell-driven photo-rechargeable lithium-ion capacitor for self-powered wearable strain sensors. Nano Energy, 2019, 60: 247-256

$17 \mathrm{Ng} \mathrm{CH}$, Lim HN, Hayase S, et al. Cesium lead halide inorganicbased perovskite-sensitized solar cell for photo-supercapacitor application under high humidity condition. ACS Appl Energy Mater, 2018, 1: 692-699

18 Liu Z, Zhong Y, Sun B, et al. Novel integration of perovskite solar cell and supercapacitor based on carbon electrode for hybridizing energy conversion and storage. ACS Appl Mater Interfaces, 2017, 9: $22361-22368$

19 Zhou F, Ren Z, Zhao Y, et al. Perovskite photovoltachromic supercapacitor with all-transparent electrodes. ACS Nano, 2016, 10: 5900-5908

$20 \mathrm{Du} \mathrm{P}, \mathrm{Hu} \mathrm{X}$, Yi C, et al. Self-powered electronics by integration of flexible solid-state graphene-based supercapacitors with high performance perovskite hybrid solar cells. Adv Funct Mater, 2015, 25: $2420-2427$

$21 \mathrm{Xu} \mathrm{J}, \mathrm{Ku} \mathrm{Z}$, Zhang $\mathrm{Y}$, et al. Integrated photo-supercapacitor based on PEDOT modified printable perovskite solar cell. Adv Mater Technol, 2016, 1: 1600074

22 Liang J, Zhu G, Lu Z, et al. Integrated perovskite solar capacitors with high energy conversion efficiency and fast photo-charging rate. J Mater Chem A, 2018, 6: 2047-2052

23 Liu R, Liu C, Fan S. A photocapacitor based on organometal halide perovskite and PANI/CNT composites integrated using a CNT bridge. J Mater Chem A, 2017, 5: 23078-23084

24 Yun S, Qin Y, Uhl AR, et al. New-generation integrated devices based on dye-sensitized and perovskite solar cells. Energy Environ Sci, 2018, 11: 476-526

25 Kim J, Lee SM, Hwang YH, et al. A highly efficient self-power pack system integrating supercapacitors and photovoltaics with an areasaving monolithic architecture. J Mater Chem A, 2017, 5: 19061912

26 Sun H, Jiang Y, Qiu L, et al. Energy harvesting and storage devices fused into various patterns. J Mater Chem A, 2015, 3: 14977-14984

$27 \mathrm{Xu} \mathrm{X,} \mathrm{Li} \mathrm{S,} \mathrm{Zhang} \mathrm{H,} \mathrm{et} \mathrm{al.} \mathrm{A} \mathrm{power} \mathrm{pack} \mathrm{based} \mathrm{on} \mathrm{organometallic}$ perovskite solar cell and supercapacitor. ACS Nano, 2015, 9: 17821787

28 Zhang Z, Chen X, Chen $\mathrm{P}$, et al. Integrated polymer solar cell and electrochemical supercapacitor in a flexible and stable fiber format. Adv Mater, 2014, 26: 466-470

29 Miyasaka T, Murakami TN. The photocapacitor: An efficient selfcharging capacitor for direct storage of solar energy. Appl Phys 
Lett, 2004, 85: 3932-3934

30 Murakami TN, Kawashima N, Miyasaka T. A high-voltage dyesensitized photocapacitor of a three-electrode system. Chem Commun, 2005, (26): 3346-3348

31 Chen X, Sun H, Yang Z, et al. A novel “energy fiber” by coaxially integrating dye-sensitized solar cell and electrochemical capacitor. J Mater Chem A, 2014, 2: 1897-1902

32 Lechêne BP, Cowell M, Pierre A, et al. Organic solar cells and fully printed super-capacitors optimized for indoor light energy harvesting. Nano Energy, 2016, 26: 631-640

33 Liu R, Wang J, Sun T, et al. Silicon nanowire/polymer hybrid solar cell-supercapacitor: A self-charging power unit with a total efficiency of 10.5\%. Nano Lett, 2017, 17: 4240-4247

34 Liu R, Liu Y, Zou H, et al. Integrated solar capacitors for energy conversion and storage. Nano Res, 2017, 10: 1545-1559

35 Simon P, Gogotsi Y. Materials for electrochemical capacitors. Nat Mater, 2008, 7: 845-854

36 Yang HC, Xie Y, Hou J, et al. Janus membranes: Creating asymmetry for energy efficiency. Adv Mater, 2018, 30: 1801495

37 Yang HC, Hou J, Chen V, et al. Janus membranes: Exploring duality for advanced separation. Angew Chem Int Ed, 2016, 55: 13398-13407

38 Wang Z, Wang Y, Liu G. Rapid and efficient separation of oil from oil-in-water emulsions using a Janus cotton fabric. Angew Chem Int Ed, 2016, 55: 1291-1294

39 Zhang Z, Kong XY, Xiao K, et al. A bioinspired multifunctional heterogeneous membrane with ultrahigh ionic rectification and highly efficient selective ionic gating. Adv Mater, 2016, 28: 144-150

40 Hou J, Ji C, Dong G, et al. Biocatalytic Janus membranes for $\mathrm{CO}_{2}$ removal utilizing carbonic anhydrase. J Mater Chem A, 2015, 3: 17032-17041

41 Zhu X, Hao J, Bao B, et al. Unique ion rectification in hypersaline environment: A high-performance and sustainable power generator system. Sci Adv, 2018, 4: eaau1665

42 Shen $\mathrm{L}$, Che Q, $\mathrm{Li} \mathrm{H}$, et al. Mesoporous $\mathrm{NiCo}_{2} \mathrm{O}_{4}$ nanowire arrays grown on carbon textiles as binder-free flexible electrodes for energy storage. Adv Funct Mater, 2014, 24: 2630-2637

43 Huang L, Chen D, Ding Y, et al. Nickel-cobalt hydroxide nanosheets coated on $\mathrm{NiCo}_{2} \mathrm{O}_{4}$ nanowires grown on carbon fiber paper for high-performance pseudocapacitors. Nano Lett, 2013, 13: 3135-3139

44 Zhang G, Lou XWD. General solution growth of mesoporous $\mathrm{NiCo}_{2} \mathrm{O}_{4}$ nanosheets on various conductive substrates as highperformance electrodes for supercapacitors. Adv Mater, 2013, 25: 976-979

45 Wei TY, Chen CH, Chien HC, et al. A cost-effective supercapacitor material of ultrahigh specific capacitances: Spinel nickel cobaltite aerogels from an epoxide-driven sol-gel process. Adv Mater, 2010, 22: $347-351$

Acknowledgements This work was supported by the National Natural Science Foundation of China (21875123 and 21421001).
Author contributions Chen P, and Gao XP conceived the idea. Chen $\mathrm{P}$ carried out the preparation and electrochemical tests of the devices. Chen P and Gao XP co-wrote the paper. All the authors contributed to the general discussion.

Conflict of interest The authors declare that they have no conflict of interest.

Supplementary information Experimental details and supporting data are available in the online version of the paper.

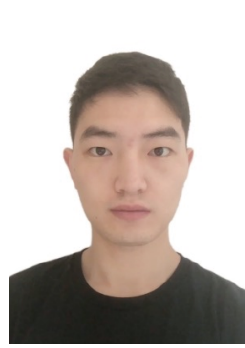

Peng Chen is currently a $\mathrm{PhD}$ candidate in the School of Materials Science and Engineering, Nankai University. He received his BSc degree in 2015 from the College of Chemistry, Nankai University of China. His general research interests are in the area of perovskite solar cells and novel solar energy storage systems like solar rechargeable batteries.

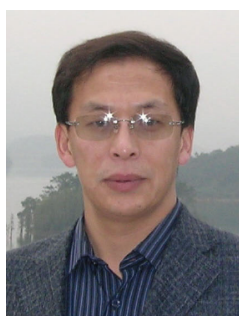

Xue-Ping Gao is a professor in the Institute of New Energy Material Chemistry, Nankai University. He received his doctorate degree at the Department of Chemistry from Nankai University in 1995 . He worked as a visiting research fellow at Kogakuin University in Japan from 1997 to 1999. Currently, his main research focuses on energy storage materials for power sources, including Li-ion batteries, Li-S battery and solar rechargeable battery.

\section{基于原位Janus修饰电极的准固态光充电容器实 现太阳能倍增效应}

陈鹏, 李田田, 李国然, 高学平 ${ }^{*}$

摘要 太阳能是最有希望取代化石能源的清洁可再生能源. 然而, 太阳辐射的功率密度偏低, 限制了太阳能的高效利用. 本文提出了 一种基于Janus修饰电极的集成式准固态光充电容器, 以实现太阳 能的倍增效应和高效利用. 利用这种集成的一体化结构单元, 可实 现太阳能功率密度的调节和放大. 该结构单元由水凝胶电解液、

不对称亲水/疏水Janus修饰的共享电极以及高效的钻钛矿太阳能 电池共同集成. 得益于特殊的Janus结构, 该准固态器件可以实现太 阳能的高效转换、储存和利用. 同时, 构建的器件功率密度可高达 $500 \mathrm{~mW} \mathrm{~cm}^{-2}$, 比普通太阳能电池输出功率高出约 50 倍. 此外, 这种 策略简单易行, 可方便拓展到其他光储能体系中, 以实现太阳能的 高效利用. 